\title{
Experimental Study on the Tensile Strength and Linear Expansion Coefficient of Air Tunnel Terrazzo Surface
}

\author{
Li Boping, Yang Hui \\ The 63926 Troop of Chinese People's Liberation Army, Beijing 100192, China
}

\begin{abstract}
At present, studies on the surface tension of air tunnel terrazzo under wind load and how regularly it is affected by temperature are relatively less, and the measured results of the thermal expansion coefficient of terrazzo have not yet been given. In this paper, based on the top terrazzo surface structure of the inner wall of the wind tunnel, the tensile performance tests of terrazzo surface layer are conducted, while the thermal expansion coefficient of the six terrazzo test blocks were tested. The tests and analysis show that the construction of terrazzo surface, based on the proposed construction process, can effectively guarantee the reliable cement performance for the binding layer between mortar and concrete base layer, terrazzo surface layer and the cement mortar layer. And the thermal expansion coefficient of terrazzo can be valued at $1.06 \mathrm{e}-5 /{ }^{\circ} \mathrm{C}$.
\end{abstract}

\section{Introduction}

Terrazzo is a concrete product made of cement as the major raw material and with gravels mixed, used to make floor tiles, countertops, sinks, decorative surface of walls etc. [1-2]. If the terrazzo is used in shaped tunnel body, the body can improve the aerodynamic flow field quality of wind tunnel. Therefore, this study is of great significance. But usually terrazzo construction is on the ground [3-4]. Constructing terrazzo on the top of shaped wind tunnel is difficult. At present, studies on how regularly the wind tunnel terrazzo layer is affected by temperature are relatively less, and the measured results of the thermal expansion coefficient of terrazzo have not yet been given, and the specimen size of terrazzo linear expansion coefficient is not clearly specified.

In this paper, the top terrazzo layer of the wind tunnel body is taken as the study object. A variety of mix ratios between cement mortar and terrazzo surface layer are prepared. And test equipment is homemade and the tensile test done, in order to get the ration and thickness of terrazzo layer, and the recommended values of key parameters such as the diameter of gravels in terrazzo layer. Meanwhile, taking the size of concrete specimen for thermal expansion coefficient into account, six terrazzo test blocks are made to test the thermal expansion coefficient.

\section{Terrazzo's Tensile Performance Test}

Based on the structure of top terrazzo layer of the wind tunnel's inner wall, when constructing specimen in lab, firstly plant steel bars into the base structure layer and hang steel mesh, apply mortar, and then fix copper strips,

\footnotetext{
${ }^{a}$ Corresponding author: jsk63926@126.com
}

copper strips are used to control precise positioning of terrazzo profile and to separate terrazzo to eliminate the adverse effects of thermal expansion and contraction, and finally the construction terrazzo is polished molding. The structure layer is as shown in Figure 1.

This test uses hydraulic loading. In the hydraulic loading device, the hydraulic jack plate is fixed on the steel base unit which is fixed on the ground. Use the device to convert the lifting force generated by manual hydraulic jack into the chuck's pull for loading, loading method shown in Figure 2.

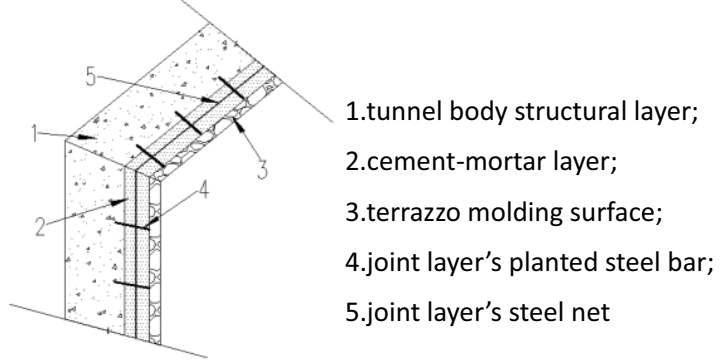

Figure 1. Diagram for the in situ concrete tunnel's inner surface

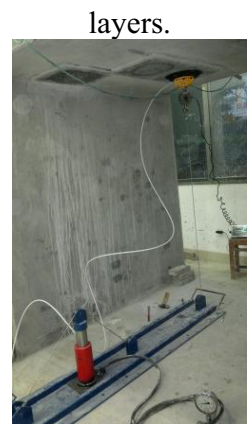

Figure 2. Loading device 


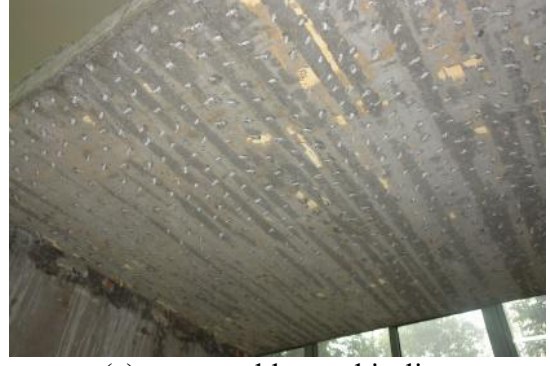

(a) structural layer chiseling

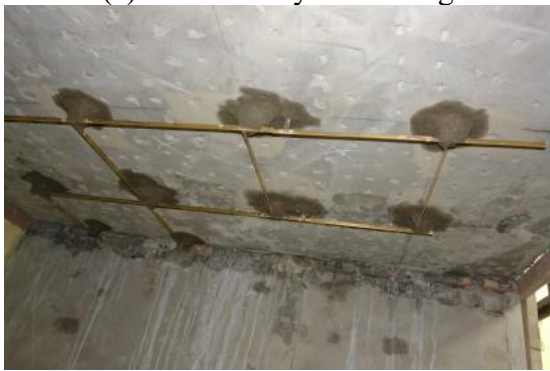

(b) fixed copper strips

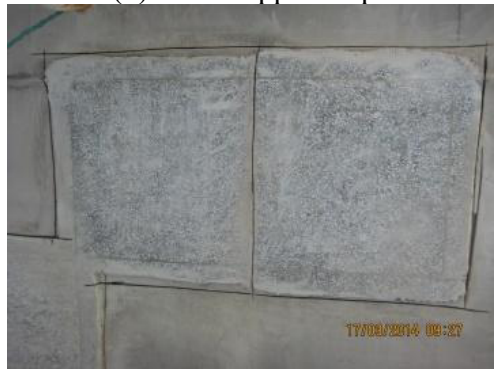

(c) completion of terrazzo construction

Figure 3. Terrazzo construction

In the test conditions, mortar and different terrazzo layers, different mix ratios, whether it be hollowed or additional steel net needed are considered. Terrazzo construction is shown in Figure 3. The analysis shows that, if the structural layer surface is chiseled, the adhesion between mortar layer and structure layer is stronger than specimens not chiseled. In all test conditions, except the specimen whose material strength does not reach the designed strength, specimens not chiseled are not destroyed, and can withstand greater suction. By examining the specimens whose terrazzo molding surface's mechanical performances are affected by steel net, as well as hollowing situation may happen on the construction site, steel mesh needs to be set at the construction site of terrazzo surface layer to enhance the adhesion performances between cement mortar layer and the base, and also to enhance the terrazzo surface's tensile mechanical performances. The hollowing area in construction may take place between the base and the mortar layer, between the mortar layer and terrazzo. When hollowing rate is low, it affects but a little the mechanical performances of terrazzo. However, higher hollowing rate has bigger impact on terrazzo's performances. On construction site, the hollowing rate can not exceed $20 \%$.

The mix ratio of the mortar layer and terrazzo, the thickness of each layer and number of smear layers affect the mechanical performances of terrazzo. As for the surface layer of cement mortar, cement and gravel mixture ratio of $1: 2 \sim 2.5$ is appropriate, the total thickness of the surface layer should be $25 \sim 30 \mathrm{~mm}$, and steel mesh should be set at the middle; for the surface layer of terrazzo, cement and gravel mix ratio of 1 : $1 \sim 1.5$ is appropriate, with desirable thickness 10 $\sim 15 \mathrm{~mm}$

What happened on the construction site and in the test shows that for terrazzo surface layer, gravel particle size should not be too large, which can easily lead to the falling of terrazzo in the construction, so as to affect the molding quality of terrazzo surface layer. The particle diameter should be $3 \sim 5 \mathrm{~mm}$.

To sum up, for terrazzo made in accordance with the actual construction process of the wind tunnel body, when wind tunnel body is put into operation during the test, the strength of cement mortar bonding layer and terrazzo surface layer of wind tunnel body is sufficient to resist the suction produced by the designed $130 \mathrm{~m} / \mathrm{s}$ wind speed load in the test. And terrazzo surface layer has sufficient safety margin.

\section{Terrazzo's linear expansion coefficient test}

Thermal expansion coefficient includes linear expansion coefficient, surface expansion coefficient and volume expansion coefficient. Linear expansion coefficient is generally used to evaluate the thermal expansion nature of material[5-6]. Here is how in physics the linear expansion coefficient is defined: when solid material' $\mathrm{s}$ temperature changes $1^{\circ} \mathrm{C}$, the rate of its length change to that of $0^{\circ} \mathrm{C}$, with $1 /{ }^{\circ} \mathrm{C}$ as the unit and as the symbol, which is defined as the formula $L_{t}=L_{0}(1+a t)$

Namely $a=\left(L_{t}-L_{0}\right) / t L_{0}$

$L_{t}$ is the model's corresponding length when at $\mathrm{t}^{\circ} \mathrm{C}$ while $L_{0}$ the model's corresponding length when at $0^{\circ} \mathrm{C}$; By reference herein to the measurements for the concrete temperature coefficient of linear expansion, six prismatic specimens with dimension of $100 \mathrm{~mm} \times 100 \mathrm{~mm} \times 515 \mathrm{~mm}$ are used in the experiments, according to the mix ratio of terrazzo designed for air tunnel construction site, mix ratio of concrete and gravel are 1: 1 and 1: 1.5 , each matching three specimens (ie, the ratio of 1: 1 has specimen 1, 2, 3; the ratio of 1: 1.5 has specimen4, 5, 6). Specimens are shown in Figure 4, after terrazzo reaches the curing time, put it in the constant temperature and humidity chamber to test the temperature sensitivity.

Record data collected by indicator, take the average of the three test pieces of the same ratio as the test result, when temperature changes terrazzo's strain is the data collected by indicator. In the early stage of this experiment, use the first method to measure the length of terrazzo, as shown in Figure 5. As a result of 
indicator erected in terrazzo specimens and put together into constant temperature and humidity chamber in this method, the temperature of erection equipment for the dial gauge rises with terrazzo specimen's temperature changing due to thermal expansion and contraction, it is found that indicator readings during the test are not very accurate. At the later stage, the test method improved, shown in Figure 6 , around the terrazzo test piece are wrapped insulation materials, first put test piece into constant temperature chamber to be heated, then put it out to measure the length, when processing data, consider the data measured by two methods, take the average value as the test results. In the test the temperature range $\triangle T$ are $0^{\circ} \mathrm{C}$, room temperature (about $20{ }^{\circ} \mathrm{C}$ ), $40^{\circ} \mathrm{C}$ and $60{ }^{\circ} \mathrm{C}$, the curve length changes with temperature should be a straight line through the origin of coordinate. Show the data in the Cartesian coordinate system, at the same time use linear regression to get the relationship between terrazzo strain and temperature so as to get terrazzo's linear expansion coefficient.

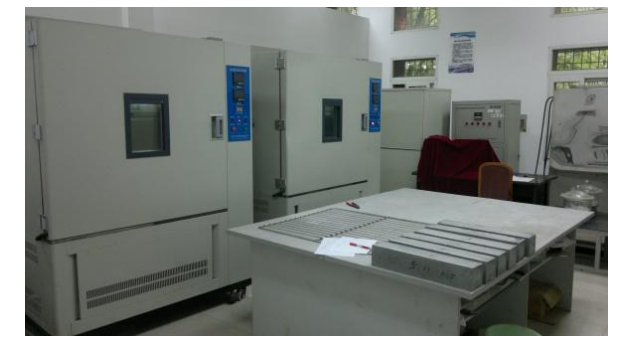

Figure 4. Terrazzo specimens

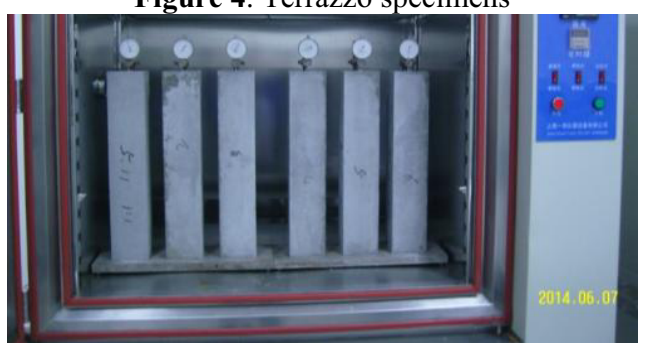

Figure 5. Method 1 for terrazzo specimen's length measurement

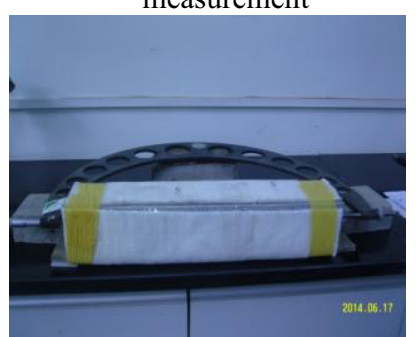

Figure 6. Method 2 for terrazzo specimen's length measurement

When measuring the length of both ends of the terrazzo specimen, iron ends are required to paste at both ends of the specimen, the length of iron end will change with temperature changing, eliminate this errors in the data processing, when at $0^{\circ} \mathrm{C}$, the length of both ends of the 6 specimens are shown in Table 1 . When processing the test data, according to Equations 1 and 2, the linear expansion coefficient of two different mix ratio terrazzos can be calculated, the results shown in Table 2 .

Table 1. The length of test specimen both ends toe

\begin{tabular}{lllllll}
\hline & $\begin{array}{l}\text { Sp1 } \\
\mathrm{mm}\end{array}$ & $\begin{array}{l}\mathrm{Sp} 2 \\
\mathrm{~mm}\end{array}$ & $\begin{array}{l}\mathrm{Sp} 3 \\
\mathrm{~mm}\end{array}$ & $\begin{array}{l}\mathrm{Sp} 4 \\
\mathrm{~mm}\end{array}$ & $\begin{array}{l}\mathrm{Sp} 5 \\
\mathrm{~mm}\end{array}$ & $\begin{array}{l}\mathrm{Sp} 6 \\
\mathrm{~mm}\end{array}$ \\
\hline length & $16+15$ & $14+14$ & $13+15$ & $17+13$ & $14+17$ & $14+17$ \\
\hline
\end{tabular}

Table 2. The linear expansion coefficient of test specimens

\begin{tabular}{llllllll}
\hline & $\mathrm{Sp} 1$ & $\mathrm{Sp} 2$ & $\mathrm{Sp} 3$ & $\mathrm{Sp} 4$ & $\mathrm{Sp} 5$ & $\mathrm{Sp} 6$ & mean \\
\hline \multirow{2}{*}{ coefficient } & $\begin{array}{l}1.16 \mathrm{e} \\
-5\end{array}$ & 9.69 & $\begin{array}{l}1.1 \mathrm{e}- \\
\mathrm{e}-6\end{array}$ & $\begin{array}{l}1.04 \\
\mathrm{e}-5\end{array}$ & $\begin{array}{l}1.04 \\
\mathrm{e}-5\end{array}$ & $\begin{array}{l}1.02 \mathrm{e} \\
-5\end{array}$ & $\begin{array}{l}1.06 \mathrm{e} \\
-5\end{array}$ \\
\hline
\end{tabular}

From the analysis above, the linear expansion coefficient of the test terrazzo is $1.06 \mathrm{e}-5 /{ }^{\circ} \mathrm{C}$

\section{Conclusion}

Through experiments, the thermal expansion coefficient of terrazzo is measured, the thermal stress response analysis of terrazzo is made, the following conclusions are made:

(1) based on engineering practice and test results, for the surface layer of cement mortar, cement and gravel mixture ratio of 1: $2 \sim 2.5$ is appropriate, the total thickness of the surface layer should be $25 \sim 30 \mathrm{~mm}$, and steel mesh should be set at the middle; for the surface layer of terrazzo, cement and gravel mix ratio of 1 : $1 \sim 1.5$ is appropriate, with desirable thickness 10 $\sim 15 \mathrm{~mm}$.

(2) for terrazzo surface layer, gravel particle size should not be too large, which can easily lead to the falling of terrazzo in the construction, so as to affect the molding quality of terrazzo surface layer.

(3) the mix ratio of terrazzo has little impact on its thermal expansion coefficient which can be valued at $1.06 \mathrm{e}-5 /{ }^{\circ} \mathrm{C}$.

(4) by the experiment, and comparing with the linear expansion coefficient of concrete given by Design Specifications for Concrete Structures(such as the linear expansion coefficient of concrete in the Specifications is $1 \mathrm{e}-5 /{ }^{\circ} \mathrm{C}$ while the linear expansion coefficient of terrazzo measured in this test is $1.06 \mathrm{e}-$ $5 /{ }^{\circ} \mathrm{C}$ ). The test results are feasible and there is sufficient accuracy. The measurement methods and data of terrazzo's linear expansion coefficient can be used for peer learning and valuing.

\section{REFERENCES}

[1] Ministry of Industry and Information Technology, People's Republic of China, JC / T507-2012 Architectural Decorative Terrazzo. Building Industry Press, 2012.( In Chinese) 
[2] Xiyan Du, Hebin Luo, Xueli Shi, "Terrazzo: Present and Prospects". Decorative Concrete, vol. 04, pp.10, 2010. ( In Chinese)

[3] Dongfeng An, Jun Guo,"Floor Construction Technology for Terrazzo". Shanxi Architecture, vol. 30, pp. 54-55, 2004. (In Chinese)

[4] Libin Qian, "In Situ Terrazzo Floor Construction for Civil Building" Private Technology, vol. 05, pp. 324, 2011. ( In Chinese)

[5] Industrial Standards of the People's Republic of China, GB50010-2010 Specifications of Concrete Structures Design. Ministry of Construction, People's Republic of China, 2010. ( In Chinese)

[6] Beibei Cao, On the Thermal Properties and Recycling of Concrete. Wuhan University of Technology, 2006. ( In Chinese) 